\title{
ANÁLISE DE PATOLOLOGIA EM SISTEMAS PREDIAIS DE CHUVEIROS AUTOMÁTICOS COM TUBOS DE COBRE
}

\author{
Pathology analysis in fire sprinkler system using copper pipes \\ MARANGONI, Liria Daniela Martins; OLIVEIRA, Lúcia Helena²
}

Recebido em 15 de julho de 2021, aprovado em 06 de setembro de 2021, publicado em 18 de novembro de 2021

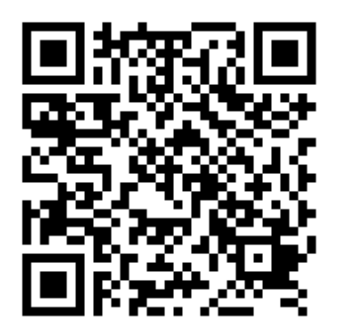

Palavras-chave:

Sistema de chuveiros automáticos;

Patologia;

vazamento.

Keywords:

Fire sprinkler system;

Pathology;

leak.

\begin{abstract}
RESUMO: A corrosão precoce em tubulações de cobre de sistemas prediais de chuveiros automáticos, verificada em edificações do Sesc e, também, relatada em diversos estudos realizados nos últimos anos, motivou o desenvolvimento desta pesquisa. Neste contexto, o objetivo deste trabalho é analisar as causas de vazamentos em um sistema de chuveiros automáticos executados com tubos de cobre antes mesmo do sistema entrar em operação. A metodologia utilizada foi a análise documental do sistema de chuveiros automáticos e a análise da patologia por meio de testes laboratoriais. Os resultados indicam que a possível causa de corrosão na tubulação de cobre foi a utilização de pasta de soldagem não hidrossolúvel, durante os serviços de montagem das tubulações do sistema. 0 excesso de fluxo de soldagem encontrado na superfície interna dos tubos foi determinante para a ocorrência de corrosão por pite a partir das superfícies internas dos tubos. Assim, uma das medidas que poderiam ter evitado esse tipo de corrosão seria a capacitação da mão de obra para a execução adequada do processo de soldagem das tubulações.
\end{abstract}

ABSTRACT: Early corrosion in copper pipes in sprinklers systems verified in Sesc buildings and reported in several studies carried out in recent years, motivated the development of this research. In this context, the aim of this paper is to analyse the causes of leaks in a sprinkler system made with copper pipes even before the system starts operating. The methodology used was the document analysis of the automatic sprinkler system and the analysis of the pathology through laboratory tests. The results indicate that the possible cause of corrosion in the copper piping was the use of non-water-soluble soldering paste during the assembly services of the system's piping. The excess of welding flux found on the inner surface of the pipes was determinant for the occurrence of pitting corrosion from the inner surfaces of the pipes. Thus, one of the measures that could have avoided this type of corrosion would be the training of the workforce for the proper execution of the pipe welding process.

\section{CONTATO DOS AUTORES:}

1 MARANGONI, Liria Daniela Martins. Enga. Civil, Especialista em Tecnologia e Gestão na Produção de Edifícios, Escola Politécnica da USP, liria.marangoni@sescsp.org.br

${ }^{2}$ OLIVEIRA, Lúcia Helena. Enga. Civil, Livre Docente, Professora da Escola Politécnica da USP, lucia.helena@usp.br 


\section{INTRODUÇÃO}

O Serviço Social do Comércio (Sesc), no estado de São Paulo, conta com 43 unidades destinadas à cultura, ao esporte, à saúde e à alimentação, ao desenvolvimento infanto-juvenil, à terceira idade, ao turismo social dentre outras áreas de atuação. Essas unidades possuem sistemas de chuveiros automáticos executados com tubulações de cobre.

Nos últimos anos têm sido verificados muitos vazamentos em conexões e soldas e, mais recentemente, vazamentos decorrentes de corrosão precoce no interior de tubulações. A conexão entre os tubos do sistema de chuveiros automáticos é executada por meio de processos de soldagem estabelecidos na NBR 15345 (ABNT, 2013) e requer mão de obra especializada para a execução.

Observa-se que o mercado possui carência dessa mão de obra especializada e isso tem sido o principal fator de falhas na execução do sistema de chuveiros automáticos, o que acarreta vazamentos decorrentes de falhas de soldagem das conexões e de furos provenientes de corrosão por pites.

Neste contexto, este trabalho apresenta um estudo sobre um sistema de chuveiros automáticos executado com tubulações de cobre que apresentou vazamentos antes mesmo de entrar em operação.

Inicialmente, foi realizada a análise documental do sistema de chuveiros automáticos como relatórios, laudos técnicos e acervo fotográfico das patologias. Em seguida, foram realizadas visitas técnicas na unidade durante a obra de correção das patologias do sistema executado com tubulação de cobre. Por fim, ocorreu a análise e o compilamento dos resultados apresentados nos testes laboratoriais para o caso em questão.

\subsection{Sistema de chuveiros automáticos}

O sistema de chuveiros automáticos é um sistema fixo de combate a incêndio e caracteriza-se por entrar em operação de modo automático e, quando ativado por um foco de incêndio, libera água em uma densidade adequada ao risco do local de modo a extinguir ou controlar o incêndio em seu estágio inicial (OLIVEIRA; GONÇALVES; GUIMARÃES, 2008).

O princípio do sistema de chuveiros automáticos é confinar o incêndio na área de operação e o princípio do componente chuveiro automático é detectar, dar o alarme e combater o fogo (CASTRO et al., 2016).

São requisitos de desempenho para o sistema de chuveiros automáticos: segurança, confiabilidade, efetividade, estanqueidade, higiene e disponibilidade, tendo em vista atender às exigências de habitabilidade do usuário em uma edificação (MARANGONI, 2021).

Os tubos de cobre utilizados nos sistemas de chuveiros automáticos são produzidos conforme especificação da NBR 13206 (ABNT, 2010) e o teor mínimo de pureza do material tem que ser de $99,9 \%$ de cobre.

As conexões entre tubos executadas por meio de processos de soldagem e/ou brasagem capilar devem atender requisitos da NBR 11720 (ABNT, 2010) e os procedimentos de execução das instalações conforme especificados na NBR 15345 (ABNT, 2013). 


\section{ESTUDO DE CASO}

Apresenta-se neste item o estudo de caso do sistema de chuveiros automáticos do Sesc Jundiaí, uma obra concluída em abril/2015, com área construída de 19.752,92 m².

\subsection{Caracterização do sistema de chuveiros automáticos}

O sistema de chuveiros automáticos adotado é o de tubo molhado e contempla 4 válvulas de governo e alarme (VGA), instaladas no subsolo, conforme ilustrado na Figura 1.

Figura 1 - Locação das VGAs no Sesc

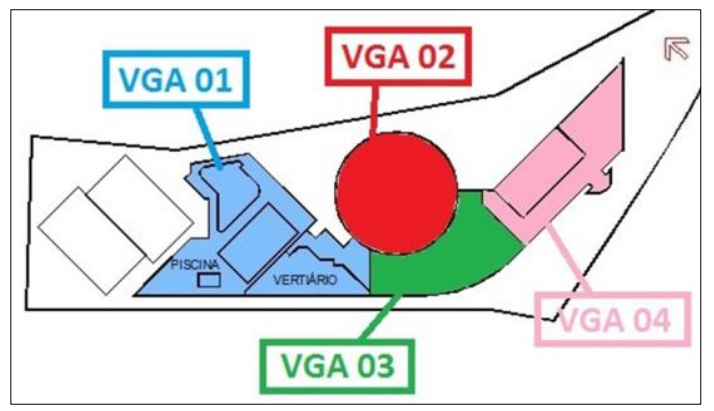

Fonte: Marangoni (2021)

O sistema é pressurizado por meio de duas eletro-bombas, a principal e a auxiliar, além de uma moto-bomba principal reserva. O comando para acionamento dessas eletro-bombas é por meio de pressostatos.

A coluna que alimenta os chuveiros automáticos possui o diâmetro de $104 \mathrm{~mm}$ e é ligada ao fundo do reservatório inferior, com uma reserva de água de 100.000 litros.

Os chuveiros automáticos possuem certificação UL e FM e são do tipo resposta rápida, pendente, para cima e lateral, rosqueável, com diâmetro de $15 \mathrm{~mm}$ e ampola de acionamento para $68^{\circ} \mathrm{C}$.

Toda a rede foi executada com tubos de cobre do tipo sem costura, classe $E$, com as junções dos tubos e conexões executadas por soldagem capilar.

\subsection{Patologias nas tubulações de cobre}

Após a conclusão das instalações, com o carregamento do sistema e início de operação na unidade em abril de 2015, surgiram inúmeros pontos de vazamentos nas tubulações do sistema de chuveiros automáticos.

Ao mapear os vazamentos, verificou-se que estes ocorriam principalmente nas conexões e ligações de tubos subgerais e nos ramais, decorrentes de falhas de soldagem, conforme ilustrado nas Figuras 2 e 3.

Foi contratada uma empresa para a execução dos serviços de reparos nas tubulações do sistema de chuveiros automáticos, que ocorreram no período de abril a agosto de 2018. Para tal, a rede de tubulações foi drenada e os pontos de vazamentos foram reparados. 
Figura 2 - Falha em soldagem de tubulação da Odontologia

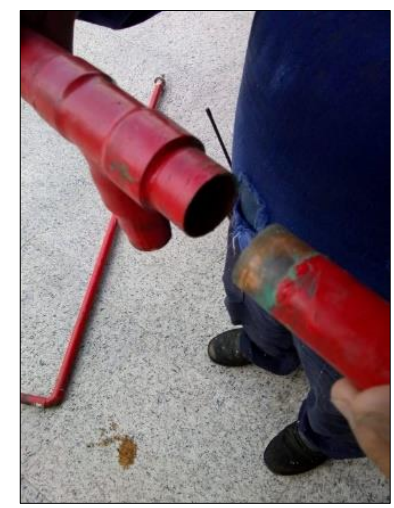

Figura 3 - Falha em soldagem de tubulação do Subsolo

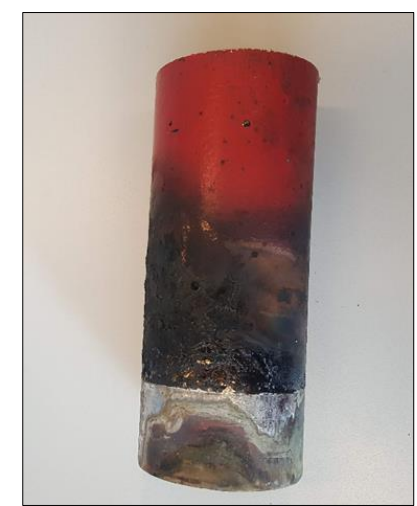

Fonte: Marangoni (2021)

Na sequência, a rede foi carregada e iniciados os testes hidrostáticos à pressão de $1380 \mathrm{kPa}$ por $2 \mathrm{~h}$, sem perdas, conforme a NBR 10897 (ABNT, 2020).

Durante os testes hidrostáticos foram detectados inúmeros furos nas tubulações quando a pressão atingiu $980 \mathrm{kPa}$, sendo necessário paralisar os testes antes de atingir a pressão de $1380 \mathrm{kPa}$. Em seguida, foram mapeados todos trechos de tubos com furos.

Os furos se concentravam nas tubulações de diâmetro $28 \mathrm{~mm}$ dos ramais, conforme ilustrado na Figura 4.

Figura 4 - Tubulações dos ramais com furos

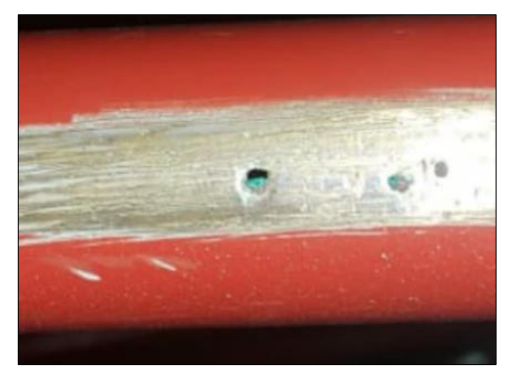

Fonte: Marangoni (2021)

A rede foi novamente drenada para o reparo dos furos. Foram então verificados vários furos por trecho de tubulações, o que inviabilizou reparos pontuais, sendo necessário substituir trechos de tubulações.

Verificou-se que as tubulações substituídas apresentavam em seu interior, resíduos de corrosão de cor verde, conforme ilustrado na Figura 5.

A fim de esclarecer as causas desses problemas e mitigar ocorrências futuras, uma vez que o Sesc Jundiaí não foi a primeira unidade a apresentar corrosão precoce no sistema de chuveiros automáticos com tubos de cobre, foram coletadas amostras das tubulações substituídas para ensaio. 
Figura 5 - Tubulações com resíduos de corrosão
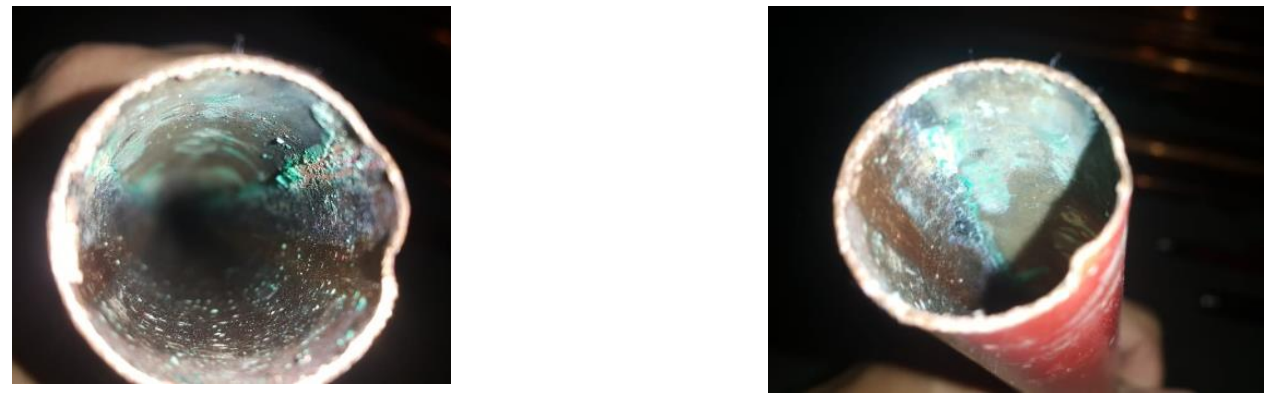

Fonte: Marangoni (2021)

Para diagnosticar as causas da patologia foram contratados ensaios com os objetivos de analisar a superfície interna e externa dos tubos de cobre, analisar os produtos de corrosão por meio de análise visual e em lupa estereoscópica. A empresa Falcão Bauer foi responsável pela execução dos ensaios.

\section{RESULTADOS}

Segundo Bauer (2019) as amostras de tubos de cobre ensaiadas não apresentam corrosão na superfície externa. No entanto, apresentam corrosão na superfície interna, com resíduos de corrosão de coloração azul-esverdeado e resíduos brancos pulverulentos nas regiões próximas à região de solda, indicando que o excesso de pasta fluxante não fora eliminado após a operação de soldagem, conforme ilustrado na Figura 6.

Figura 6 - Tubos com resíduos de corrosão
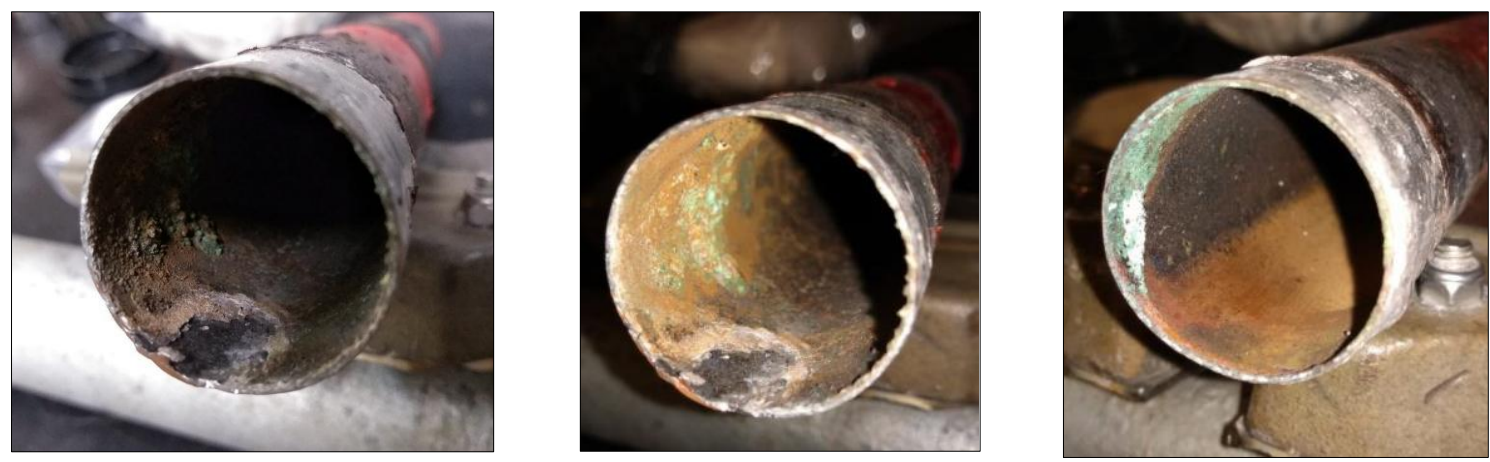

Fonte: Bauer (2019)

Na Figura 7 estão ilustradas as observações visuais. Ressalta-se que, na superfície externa não foram encontrados indícios de corrosão, sendo encontrado somente pite de corrosão. 
Figura 7 - Superfície externa do tubo ensaiado

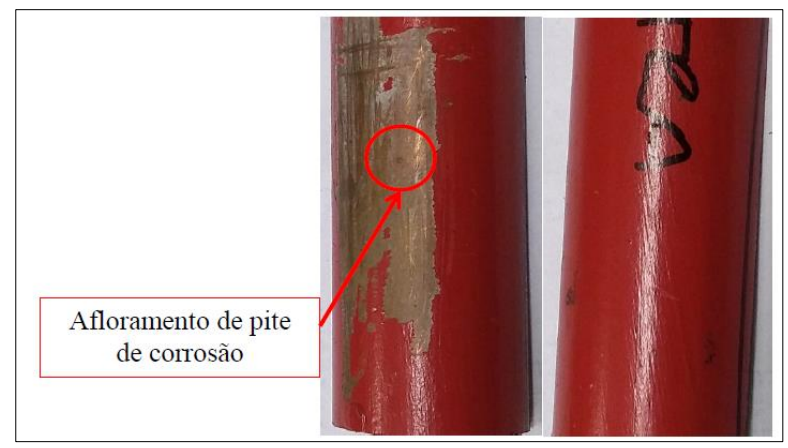

Fonte: Bauer (2019)

Na Figura 8 estão ilustradas as evidências de corrosão generalizada de coloração preta e verde e formação de pites de corrosão nas paredes internas do tubo.

\section{Figura 8 - Tubo de cobre com superfície interna apresentando pites e produtos de corrosão esverdeado}
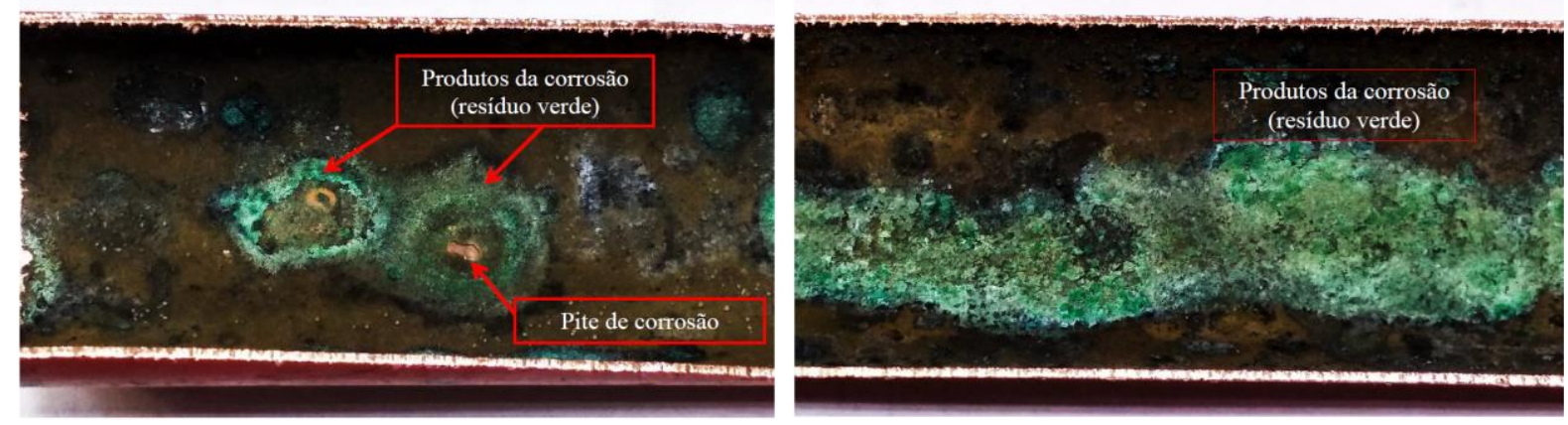

Fonte: Bauer (2019)

Na Figura 9 está ilustrada a superfície interna do tubo de cobre vista em lupa estereoscópica com maiores aumentos. Nela, observam-se detalhes dos pites de corrosão e produtos de corrosão no tubo. 
Figura 9 - Superfície interna de tubo de cobre com pites e produtos de corrosão

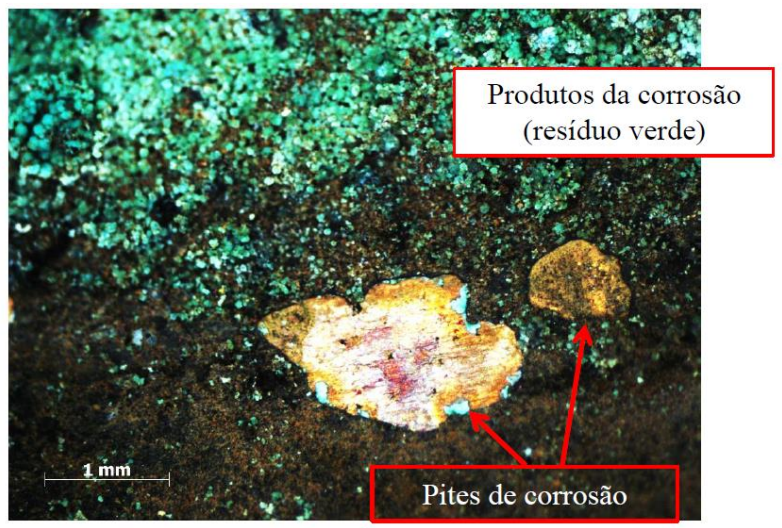

Fonte: Bauer (2019)

As evidências encontradas por meio de análise com microscópio eletrônico indicam a presença de sais de cálcio depositados nas paredes dos tubos de cobre, o que dificulta a formação de uma película passiva homogênea, capaz de proteger a superfície interna do tubo contra corrosão.

Os depósitos presentes são provenientes do processo de instalação da tubulação, tais como resíduos de material de construção e metal e fluxo de solda, que atuam como agentes que impedem a formação de uma camada com características protetoras. Além disso, o fluxo de solda contém elementos agressivos que impedem a formação de óxidos protetores.

Foi detectada a presença de resíduos de fluxo de solda nas paredes internas do tubo de cobre. A presença de pasta de solda no interior da tubulação, em regiões próximas da junta soldada indica que a tubulação não passou por operações de lavagem após soldagem.

Além disso, caso tenha sido usada pasta de solda não hidrossolúvel, a simples passagem de água na tubulação não remove o fluxo aderido às paredes, deixando resíduos de pasta fluxante com elevado teor de cloro.

Os resultados da análise química das superfícies externa e interna, respectivamente, mostram uma alta concentração do oxigênio, assim como a presença do cloro, o que resulta na formação dos produtos de corrosão identificados nas paredes internas do tubo, tais como as camadas preta e castanha que são óxidos de cobre e as camadas de coloração esverdeada, que são ricos em cloro e cobre, respectivamente.

As evidências mostram que a corrosão se inicia no interior dos tubos, com a formação de pites de corrosão que, em alguns casos, chegaram a ser perfurantes.

Bauer (2019) conclui que a possível causa de corrosão na tubulação de cobre do Sesc Jundiaí, seja a utilização de pasta de soldagem não hidrossolúvel, durante os serviços de montagem da rede de tubulações do sistema de chuveiros automáticos.

\section{CONSIDERAÇÕES FINAIS}

O excesso fluxo de soldagem encontrado na superfície interna dos tubos foi determinante para a ocorrência de corrosão por pite a partir das superfícies internas dos tubos.

As medidas que poderiam ter evitado esse tipo de corrosão: 
- contratar somente mão de obra qualificada, a fim de evitar excesso de pasta de soldagem durante o processo de solda das tubulações;

- utilizar pasta de soldagem hidrossolúvel, para evitar a presença de teores elevados de cloretos aderidos às paredes internas dos tubos de cobre; e

- executar procedimento de lavagem da tubulação no término da montagem, a fim de remover resíduos de obra e da pasta de soldagem (hidrossolúvel).

Ressalta-se que a patologia foi agravada pela utilização inadequada de materiais de soldagem e ausência de procedimentos de limpeza no interior das tubulações, após a finalização da montagem das redes.

Este material, quando executado conforme os procedimentos especificados na NBR 15345 (ABNT, 2013), segundo as orientações do fabricante e com mão de obra qualificada, requer pouca manutenção.

\section{REFERÊNCIAS}

ASSOCIAÇÃO BRASILEIRA DE NORMAS TÉCNICAS. NBR 10897: Sistemas de proteção contra incêndios por chuveiros automáticos. Rio de Janeiro, 2020.

ASSOCIAÇÃO BRASILEIRA DE NORMAS TÉCNICAS. NBR 15345: Instalação predial de tubos e conexões de cobre e ligas de cobre. Rio de Janeiro, 2013.

ASSOCIAÇÃO BRASILEIRA DE NORMAS TÉCNICAS. NBR 13206: Tubo de cobre leve, médio e pesado. Rio de Janeiro, 2010.

ASSOCIAÇÃO BRASILEIRA DE NORMAS TÉCNICAS. NBR 11720: Conexões para união de tubos de cobre por soldagem ou brasagem capilar. Rio de Janeiro, 2010.

BAUER, F. Análise de corrosão em tubos de cobre 6B e 16B. São Paulo, 2019. 17p. Relatório de Ensaio no MEC-032.222/18.

CASTRO, A.C.O.; MENDES, C.F.; OLIVEIRA, L.H. Sistemas Prediais de Chuveiros Automáticos. São Paulo: EPUSP, 2016. 46p. (Texto Técnico) Escola Politécnica da USP, Departamento de Engenharia de Construção Civil).

MARANGONI, L.D.M. Análise comparativa de custos entre sistemas prediais de chuveiros automáticos com tubos de cobre e conexões soldadas e com tubos de aço carbono e acoplamento mecânico ranhurado. 2021. 126 f. Monografia (Especialização. Escola Politécnica da Universidade de São Paulo), São Paulo, 2021.

OLIVEIRA, L. H.; GONÇALVES, O. M.; GUIMARÃES, A. P. A segurança contra incêndio no Brasil. Sistema de chuveiros automáticos, São Paulo, p. 239-255, 2008. Disponível em: http://www.ccb.policiamilitar.sp.gov.br/portalcb/_publicacoes/books/aseguranca_contra_incendio_ no_brasil.pdf. Acesso em: 03 mai. 2021. 